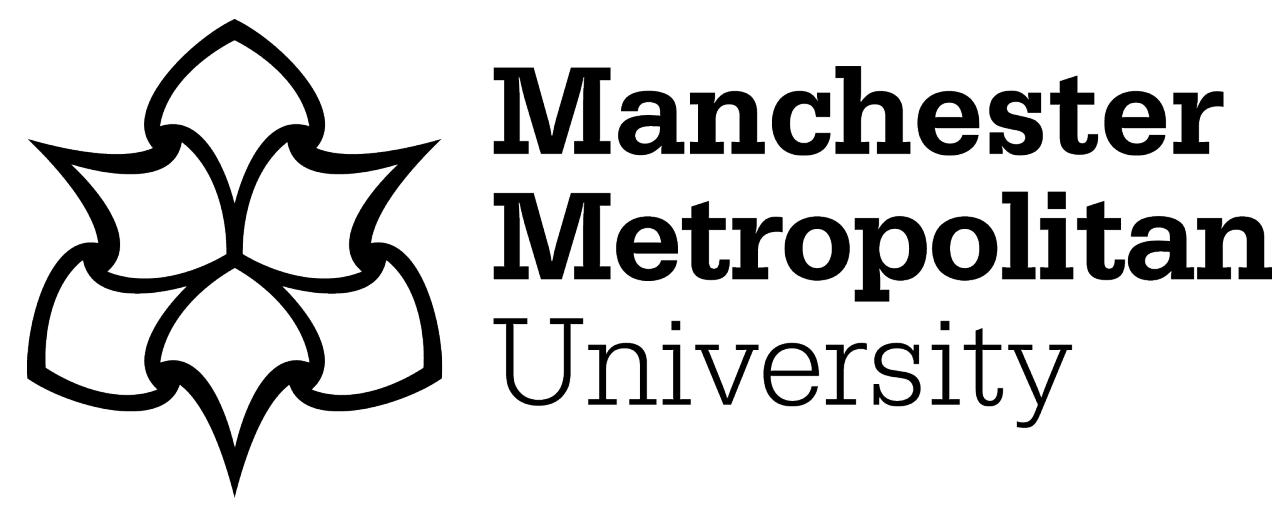

Parker, Zachary J ORCID logoORCID: https://orcid.org/0000-0002-83492172 and Waller, Glenn (2019) Psychotherapists' reports of technique use when treating anxiety disorders: factors associated with specific technique use. Cognitive Behaviour Therapist, 12. ISSN 1754-470X

Downloaded from: https://e-space.mmu.ac.uk/623202/

Version: Published Version

Publisher: Cambridge University Press (CUP)

DOI: https://doi.org/10.1017/s1754470x19000205

Please cite the published version 


\title{
Psychotherapists' reports of technique use when treating anxiety disorders: factors associated with specific technique use
}

\author{
Zachary J. Parker ${ }^{1, *}$ (iD and Glenn Waller ${ }^{2}$ (D) \\ ${ }^{1}$ Department of Psychology, Manchester Metropolitan University, Manchester, UK and ${ }^{2}$ Department of Psychology, \\ University of Sheffield, Sheffield, UK \\ ${ }^{\star}$ Corresponding author. Email: z.parker@mmu.ac.uk
}

(Received 26 February 2019; revised 29 April 2019; accepted 30 April 2019)

\begin{abstract}
Cognitive behavioural therapy (CBT) is the most efficacious and effective psychological intervention for treating anxiety disorders. Behavioural techniques, in particular exposure-based techniques, are fundamental to positive outcomes. However, research suggests that these techniques are either not used or are under-used when treating anxiety disorders. This study assesses therapists' reported use of CBT techniques in the treatment of anxiety disorders, and explores which therapist variables influence technique use. A total of $173 \mathrm{CBT}$ therapists completed measures on their demographics, routine therapy practices in treating anxiety disorders, and internal states (e.g. self-esteem). These data were analysed to see how often therapists employed particular techniques and the correlates of the use of those techniques. Behavioural techniques (e.g. exposure) were the least utilized set of core CBT skills, being used less often than non-CBT techniques. The under-utilization of these key techniques was associated with greater levels of increased inhibitory anxiety amongst therapists. Supervision and therapists' self-esteem were both positively associated with the use of non-CBT techniques. While this study established what CBT therapists purport to use in routine practice with anxious populations, further research is needed to assess the association between adherence (or lack thereof) and client outcomes, and the factors that drive non-adherence.
\end{abstract}

\section{Key learning aims}

As a result of reading this paper, the reader should:

(1) Learn about what psychotherapists report as occurring in routine care for individuals with anxiety and related disorders.

(2) Know the potential therapist traits that influence the use of CBT techniques.

(3) Gain knowledge to help explain to clients why previous therapy may not have been effective.

(4) Develop a richer understanding of what factors may influence their own therapeutic practice.

Keywords: evidence-based practice; psychotherapy process; service evaluation; therapist competence; treatment adherence

\section{Introduction}

Anxiety disorders are among the most prevalent psychological disorders. The most effective psychological treatments for anxiety, trauma and obsessive disorders come from the cognitive behavioural therapy (CBT) paradigm (e.g. Bradley et al., 2005; Eddy et al., 2004; Fedoroff and Taylor, 2001; Hofmann and Smits, 2008; Norton and Price, 2007; Otto et al., 2000; Westen and Morrison, 2001). However, labelling therapy as 'CBT' does not mean that the client 
actually receives effective or evidence-based CBT. If CBT is delivered inadequately or inappropriately, there is a risk of prolonged suffering for clients who receive such treatment for these disorders.

Such therapist drift (Waller, 2009) can occur in the selection of treatments and in their delivery. Stobie et al. (2007) found evidence of both of these phenomena in a study of 'treatment refractory' clients suffering from obsessive compulsive disorder (OCD). They found that $60 \%$ of the initial sample had received sub-optimal treatments, which were likely to be less effective than the evidence base would suggest could be achieved. Furthermore, of the $40 \%$ who were offered the most effective treatments, only $40 \%$ received a minimally acceptable dose of therapy, due to key elements being omitted. In other words, only approximately $16 \%$ of the original sample had received a full evidence-based treatment. This report and others (e.g. Hansen et al., 2002; Waller et al., 2012) indicate that what goes on in the therapy room is commonly sub-optimal, at least in the treatment of OCD and some other disorders.

There are many potential reasons for therapy techniques not being adequately delivered, which have been explored over the years (see Meehl, 1986; Waller, 2009). These factors include issues related to both professional and personal characteristics. Professional characteristics in this situation include: level of training; core profession; and work environment (e.g. number of hours in contact with clients with anxiety disorders, amount of supervision received). Personal characteristics include the therapist's own levels of anxiety and self-esteem. However, neither element exists in a vacuum and the two elements may influence each other. Therefore, these two factors need to be explored jointly. As such professional attitudes, which may derive from both personal and professional characteristics, need to also be considered.

Considering professional characteristics, Waller (2009) pointed out that therapists may make mistakes due to context-driven behaviours. Such behaviours may include being fatigued due to being overworked. Another professional characteristic that may play a role is training. As indicated by Becker et al. (2004), a significant proportion of psychologists working with posttraumatic stress disorder did not have training in exposure. A lack of initial training, mixed with personal beliefs (discussed below), may further push a psychotherapist from correcting their misconceptions (Olantunji et al., 2009; Parker and Waller, 2017). However, it is important to note that Becker et al. (2004) conducted their research with a US sample and this study involves a UK sample. In addition, no similar study has been conducted looking at training of CBT therapists in the UK. However, it is important to note that research (Brosan et al., 2006) suggests that therapists with additional post-qualification training may perceive their own skills, abilities and limitations more accurately.

Considering personal characteristics, anxiety (Koch et al., 2007; Levita et al., 2016; Parker and Waller, 2017) appears to be the primary factor that causes therapists to avoid key CBT techniques. For example, when asking a client to engage in exposure a therapist has no idea how a client may respond. Being unable to see into the future, a therapist may experience anxiety in the form of prospective anxiety that may inhibit their behaviours. Prospective anxiety and behavioural inhibition are key aspects in tolerance of uncertainty (Carleton et al., 2007; Dugas et al., 1997; Ladouceur et al., 2000). Having a lower tolerance of uncertainty may drive therapists to engage in safety-seeking behaviours to avoid negative responses (Waller, 2009) and their own negative emotions (Ladouceur et al., 2000). Therefore, psychotherapists with a greater intolerance of uncertainty may be less likely to use certain CBT techniques, such as exposure.

Considering self-esteem, it is unclear how a therapist's own levels of self-esteem influence their work. Self-esteem can be considered in relation to two factors: cognitive vulnerability-stress interactions, and self-assessment of skill and outcome. Considering the former, intolerance of uncertainty (and anxiety overall) is greatly influenced by cognitive schemas and core beliefs (Hawkes and Provencher, 2011); key components in the cognitive vulnerability-stress theory. From this perspective, therapists with greater self-esteem may be more likely than those with lower self-esteem to use challenging techniques (such as exposure). However, Metalsky et al. (1993) suggest that higher self-esteem may buffer against cognitive vulnerability-stress 
interactions. This buffer means that therapists may be less likely to blame themselves for poor therapeutic outcomes as they are less likely to attribute these failures to internal traits. However, as indicated by previous research (e.g. Stobie et al., 2007), therapists may incorrectly then attribute these failures to the client. Considering self-assessment, therapists may use higher levels of self-esteem to protect their professional identities (Parker and Waller, 2015). As a result, psychotherapists may not accurately understand their own abilities and how their skills relate to client outcomes (Brosan et al., 2006; Brosan et al., 2008; Parker and Waller, 2015). Therefore, more data are needed to better understand the interaction of self-esteem on technique use.

Finally, considering professional attitudes, therapists' own internal factors influence which techniques therapists are likely to employ. These factors include negative attitudes to manuals and protocols (Addis and Krasnow, 2000; Addis et al., 1999; Becker et al., 2004; Deacon et al., 2013; Olantunji et al., 2009; Parker and Waller, 2017). It is unclear what the source of these belief systems and attitudes may be. However, it is clear that many therapists hold false beliefs about key techniques around exposure (Olantunji et al., 2009). It is also clear that even amongst CBT therapists, negative attitudes towards CBT have an impact on technique use (Parker and Waller, 2017). However, it is likely that we do not yet have an adequate understanding of those therapist factors.

Therefore, this paper aims to determine what CBT techniques CBT therapists report using when treating anxiety disorders. In achieving this aim, this paper aims to determine the frequency of technique use and which professional and personal characteristics influence the use of these techniques. Considering professional characteristics, this paper looks to explore potential differences based on professional characteristics. With regard to personal characteristics, this paper will explore internal traits (i.e. anxiety). In addition, this paper will explore the relationship between attitudes (which in professionals may be derived from personal beliefs) and technique use.

\section{Methods}

\section{Ethics}

This study received ethical approval from the University of Sheffield, Department of Psychology Research Ethics Committee. It met the criteria of the Ethical Principles of Psychologists and the Code of Conduct (American Psychological Association, 2003).

\section{Design}

This was a cross-sectional study of mental healthcare providers whose primary theoretical orientation was CBT and who worked with anxious clients. The study was conducted using a survey and self-report inventories. Data were analysed using correlational and comparative methods.

\section{Participants}

The sample consisted of 173 UK therapists who reported their primary theoretical orientation as CBT and that they worked with clients with anxiety disorders. A total of 1965 therapists were approached directly to participate in this study, via four workshops and two online databases. The email approaches were made to 1286 therapists from the British Psychological Society and 537 therapists from the British Association for Behavioural and Cognitive Psychotherapies. Of those approached in this way, 280 therapists began the survey. Of those, 146 did not complete enough of the measures for inclusion. Most of them stopped at or during the Therapy Methods Questionnaire (TMQ). Of the remaining 134 responses, 90 reported that CBT was their primary theoretical orientation. Of those at the workshops, 82 therapists started the paper version of the measures. All 82 responses were included in analysis. Four more therapists were approached via snowball methods, but only one reported CBT as their primary theoretical orientation, and could be included. Thus, 173 UK therapists who primarily used CBT and reported on their use of CBT techniques for anxiety disorders were included in analysis. 
Table 1. Sample $(n=173)$ professional demographics

\begin{tabular}{llc}
\hline Professional demographics & $n$ & Percentage \\
\hline Profession & 44 & $25.4 \%$ \\
Clinical psychologists & 31 & $17.9 \%$ \\
Psychiatric nurses & 21 & $12.1 \%$ \\
CBT therapists & 14 & $8.1 \%$ \\
Counselling psychologists & 9 & $5.2 \%$ \\
Licensed professional counsellors & 5 & $2.9 \%$ \\
Clinical social workers & 2 & $1.2 \%$ \\
Psychiatrists & 43 & $24.9 \%$ \\
Other mental healthcare professionals & 4 & $2.5 \%$ \\
Unreported & & Mean \\
\hline Practice characteristics & 11.3 & $S D$ \\
\hline Years of clinical experience & 31.0 & $(10.29)$ \\
Hours worked per week & 12.6 & $(11.43)$ \\
Hours spent face-to-face with clients with anxiety disorders per week & $(6.65)$ \\
Hours of supervision received per month & 2.65 & $(1.97)$ \\
Hours supervising others per month & 4.71 & $(8.83)$ \\
\hline
\end{tabular}

\section{Sample characteristics}

The mean age of the sample was 45.4 years $(S D=11.15)$, and $68.2 \%$ were female. Table 1 presents the sample professional demographics, including core profession and professional characteristics.

Considering their practice with clients with anxiety disorders, therapists reported a mean of 11.5 sessions ( $S D=5.61$; range $4-60)$ before treatment was completed. The modal session length was $45-90$ minutes $(94.8 \%)$. The second most frequent session length was under 45 minutes (4.6\%). The least frequent session length was greater than 90 minutes $(0.6 \%)$.

\section{Measures}

\section{Demographics}

All participants were asked to report their general demographic details (age, gender and ethnicity) and information about their clinical characteristics [core profession; theoretical orientation; professional accreditation; hours worked per week; hours spent with anxious clients per week; hours spent in supervision (giving and receiving) per month; average session length; and approximately how many sessions were delivered before treatment was completed].

\section{Therapy Methods Questionnaire}

The TMQ consists of 26 therapy techniques. Therapists rated (on a $0-100 \%$ scale) how often they used those techniques in clinical practice with anxiety disorders ( $0 \%$ : never used; $50 \%$ : used in half of such sessions; $100 \%$ : used in every session). Techniques on this scale (see Table 2) were grouped a priori into clusters (i.e. psychoeducational and general CBT techniques, cognitive techniques, behavioural techniques, and non-CBT techniques). Previous research (Parker and Waller, 2017) has used the same grouping of techniques, and found that they had strong internal consistency (Cronbach's alpha $=.71$ to .87 ).

The scale was derived from the current literature and from treatment manuals (Abramowitz et al., 2012; Clark, 2007; Clark and Beck, 2010; Craske and Barlow, 2008; Franklin and Foa, 2008; Kearney, 2005; Martin, 2013; Resick et al., 2008; Turk et al., 2008; Whittal and Robichaud, 2012). The items were classified based on core elements for treating anxiety disorders. Some items (e.g. 'Give the client homework') were left vague and open to interpretation by the therapist and to allow for more freedom in response (although following up on homework may be a more 
Table 2. Mean levels (0 to 100) of use of each therapy technique reported by therapists (grouped by subscale)

\begin{tabular}{|c|c|c|}
\hline \multirow{2}{*}{$\begin{array}{l}\text { Cluster } \\
\text { Technique }\end{array}$} & \multicolumn{2}{|c|}{ Frequency } \\
\hline & Mean & SD \\
\hline \multicolumn{3}{|l|}{ Psychoeducation and general CBT techniques } \\
\hline Set an agenda for the session & 70.37 & $(33.42)$ \\
\hline Give the client homework & 80.11 & $(25.42)$ \\
\hline Have your client do reading on their anxiety problem & 54.08 & $(31.46)$ \\
\hline Help your client to develop new skills or to regain former skills & 69.95 & $(25.90)$ \\
\hline Draw diagrams explaining the problem, which link thoughts, feelings and behaviours & 68.30 & $(28.66)$ \\
\hline Draw diagrams showing the patterns your client has in relating to people & 33.70 & $(30.41)$ \\
\hline Overall mean for subscale & 62.79 & $(17.82)$ \\
\hline \multicolumn{3}{|l|}{ Cognitive techniques } \\
\hline Have your client keep thought records or diaries & 64.27 & $(26.62)$ \\
\hline Concentrate on anxiety-producing beliefs & 68.59 & $(26.55)$ \\
\hline Address the meaning attached to thoughts & 73.33 & $(25.46)$ \\
\hline \multirow[t]{2}{*}{ Work with your client to alter interpretation of thoughts } & 67.26 & $(31.98)$ \\
\hline & 68.28 & $(22.03)$ \\
\hline \multicolumn{3}{|l|}{ Behavioural techniques } \\
\hline Use imaginal exposure techniques in your office & 45.27 & (30.07) \\
\hline Use in vivo exposure techniques in your office & 44.51 & $(28.02)$ \\
\hline Have your client do exposure exercises outside the office with you present & 30.86 & (30.76) \\
\hline Use flooding as a form of exposure & 13.25 & $(26.19)$ \\
\hline Use systematic desensitization as a form of exposure & 48.15 & $(33.94)$ \\
\hline Overall mean for subscale & 36.13 & $(22.03)$ \\
\hline \multicolumn{3}{|l|}{ Non-CBT techniques } \\
\hline Explore patterns of relating to people in the client's life & 56.98 & (31.74) \\
\hline Use reflective listening & 83.14 & $(27.20)$ \\
\hline Offer unconditional positive regard & 79.07 & $(27.45)$ \\
\hline Explore the client's childhood, in order to understand the present better & 45.58 & $(31.04)$ \\
\hline Use silence as a therapeutic tool & 26.33 & $(27.40)$ \\
\hline $\begin{array}{l}\text { Remain silent for most of the session, allowing your clients to talk freely about whatever was on } \\
\text { their mind at the time }\end{array}$ & 14.07 & $(22.77)$ \\
\hline Focus on transference and the emotional relationship in the room & 28.19 & $(29.77)$ \\
\hline Focus on defence mechanisms & 31.08 & $(32.07)$ \\
\hline $\begin{array}{l}\text { Spend time in sessions looking at problems other than the anxiety disorder itself } \\
\text { (e.g. relationship problems) }\end{array}$ & 35.67 & $(27.16)$ \\
\hline Role-play where the client plays someone else and the therapist plays the client & 25.91 & $(26.22)$ \\
\hline Overall mean for subscale & 46.41 & $(14.66)$ \\
\hline
\end{tabular}

important factor to consider). The a priori grouping was established for another study and may pose some issues (discussed below). For further details on the creation of this scale please see Parker and Waller (2017).

\section{Intolerance of Uncertainty Scale - Short Form (IUS-12)}

The IUS-12 (Carleton et al., 2007) is a 12-item self-report measure of intolerance of uncertainty with two subscales - inhibitory anxiety and prospective anxiety. Intolerance of uncertainty is a core component of anxiety. The measure has strong psychometric properties and has been used in a range of studies (Carleton et al., 2007; Khawaja and Lai, 2010). Higher scores indicate greater levels of anxiety.

\section{Rosenberg Self-Esteem Scale (RSES)}

The RSES (Rosenberg, 1965) is a 10-item self-report measure of global self-worth. The RSES has strong psychometric properties (Schmitt and Allik, 2005; Sinclair et al., 2010). Higher scores indicate greater self-esteem. 


\section{Negative Attitudes towards CBT Scale (NACS)}

The NACS (Parker and Waller, 2017) is a 16-item self-report of therapists' negative attitudes to CBT. The NACS is a unitary scale, with strong internal consistency and validity. Higher scores indicate more negative attitudes towards CBT. The overall Cronbach's alpha for the scale is reported at .95 (Parker and Waller, 2017). In addition, this measure has also displayed strong predictive validity with regard to technique use on the TMQ and other similar measures.

\section{Procedures}

Each participant completed self-report measures of demographic details, which therapy methods they employed, anxiety, self-esteem, and negative attitudes towards CBT. Responses were included for analysis if participants reported on therapy methods employed. Any answers given as a range were averaged (e.g. '2-3' was treated as 2.5 ). If a written response was unreadable, the item was treated as having a missing value.

\section{Data analysis}

SPSS version 22 was used throughout. To determine the frequency of technique use, a repeated measures ANOVA was conducted. Considering the impact of professional characteristics on technique use, multiple approaches were used. First, one-way ANOVAs were conducted to test for differences between professional groups and their use of each of the technique groups. Second, practice characteristics were assessed in relation to technique use with the use of linear regressions. To finish assessing this aim, an independent samples $t$-test was conducted to assess differences between those with additional professional accreditation and those without. To assess personal characteristics in relation to technique use, a linear regression was conducted.

\section{Results}

\section{Use of techniques}

Table 2 shows how often therapists reported using specific techniques while treating anxiety disorders. The techniques were grouped as described in the Method section.

A repeated measure ANOVA revealed a significant difference in the frequency with which therapists used different types of technique when delivering CBT (Wilks' lambda $=.396$, $F(3,158)=79.42, p<.001)$. Cognitive techniques (mean $=68.42, S D=22.00)$ were the most frequently used. General and psychoeducational techniques (mean $=62.63, S D=17.91$ ) were the second most commonly used. The next most frequently used set of techniques were non-CBT techniques $\quad($ mean $=46.16, S D=14.52)$. Finally, behavioural techniques $\quad($ mean $=35.82$, $S D=21.64)$ were used the least. The means reported here vary slightly from those reported in Table 2, as cases with missing values were excluded for the repeated measures analysis. Bonferroni corrected $t$-tests showed that there were significant differences in the frequency of delivery between all therapy techniques $(p<.001$ in all cases).

\section{Relationship between demographic factors and technique use}

Profession

Table 3 shows the results of one-way ANOVAs assessing the association between the use of techniques and therapists' core profession. Counselling psychologists were most likely to use behavioural techniques. There were no other such differences.

Considering professional accreditation, multiple independent samples $t$-tests were conducted to look for differences between professional with post-qualification accreditation on the use of each technique cluster. In all cases, no differences were found ( $p>.150$, in all cases). 
Table 3. Technique clusters associated with core profession

\begin{tabular}{|c|c|c|c|c|c|c|c|c|}
\hline \multirow[b]{2}{*}{ Technique cluster } & \multicolumn{5}{|c|}{ Profession } & \multicolumn{3}{|c|}{ ANOVA } \\
\hline & $\begin{array}{l}\text { Counselling } \\
\text { psychologist } \\
\begin{array}{c}(1) \\
n=14\end{array}\end{array}$ & $\begin{array}{c}\text { Psychiatric } \\
\text { nurse } \\
(2) \\
n=31\end{array}$ & $\begin{array}{c}\text { Other (3) } \\
n=59\end{array}$ & $\begin{array}{c}\text { CBT } \\
\text { therapist (4) } \\
n=21\end{array}$ & $\begin{array}{c}\text { Clinical } \\
\text { psychologist } \\
\text { (5) } \\
n=44\end{array}$ & $F$ & $p$ & MC \\
\hline CBT techniques & $60.66(10.61)$ & $60.27(14.64)$ & $55.76(13.89)$ & $52.82(16.11)$ & $52.12(13.60)$ & 2.08 & .087 & - \\
\hline $\begin{array}{l}\text { Psychoeducation/ } \\
\text { general }\end{array}$ & $64.02(13.01)$ & $67.63(18.74)$ & $65.48(17.43)$ & $58.86(20.19)$ & $56.67(17.00)$ & 2.38 & .054 & - \\
\hline $\begin{array}{l}\text { Cognitive } \\
\text { techniques }\end{array}$ & $66.79(21.67)$ & $73.49(20.52)$ & $70.02(21.77)$ & $71.13(23.62)$ & $61.62(22.36)$ & 1.55 & .191 & - \\
\hline $\begin{array}{l}\text { Behavioural } \\
\text { techniques }\end{array}$ & $51.16(23.00)$ & $39.68(22.52)$ & $33.23(20.39)$ & $28.47(19.33)$ & $37.27(22.80)$ & 2.82 & .027 & $1>3$ \\
\hline $\begin{array}{l}\text { Non-CBT } \\
\text { techniques }\end{array}$ & $50.55(11.17)$ & $43.88(15.53)$ & $40.13(15.59)$ & $40.87(17.06)$ & $44.45(14.88)$ & 1.51 & .202 & - \\
\hline
\end{tabular}

Multiple comparison (MC) tests used Bonferroni corrections.

\section{Practice characteristics}

Table 4 presents the findings of multiple (stepwise) linear regressions examining the associations of therapists' practice characteristics [i.e. hours worked per week, hours spent with clients (with anxiety disorders) per week, average number of sessions when treating a client with an anxiety disorder, and supervision given/received per month] with the use of different types of technique (i.e. general and rapport techniques; cognitive techniques; behavioural techniques; non-CBT techniques). These analyses were preceded by preliminary correlations. No analysis is reported regarding the use of behavioural techniques, as there were no significant associations between therapists' demographics and the use of behavioural techniques $(r<.128$ in all cases). In the regressions, the demographics associated the most often with techniques used were hours spent with clients with anxiety disorders per week and hours worked per week. However, the number of hours of supervision that a therapist received per month was positively associated with their use of non-CBT techniques.

\section{Therapist mood and beliefs}

Table 4 presents the findings of multiple linear regressions (stepwise) examining the association between therapists' internal characteristics (i.e. anxiety, self-esteem and attitudes) with therapists' use of the different technique groups (i.e. general and rapport techniques; cognitive techniques; behavioural techniques; non-CBT techniques). No analysis is reported regarding cognitive techniques, as there were no significant associations between therapists' internal characteristics and their use of cognitive techniques in preliminary correlational analyses ( $r<-.111$ in all cases). Therapists' own levels of anxiety (inhibitory and prospective) and their attitudes towards CBT were negatively associated with the use of CBT techniques, while self-esteem was positively associated with the use of non-CBT techniques.

\section{Discussion}

The aim of this study was to determine patterns of use of CBT techniques in the treatment of anxiety disorders and the therapist factors that might influence those patterns of use. The most noteworthy point was that the most effective, evidence-based cluster of techniques (i.e. behavioural) were the least commonly used. Behavioural techniques were more likely to be used by counselling psychologists than any other professional groups. However, overall, and supporting the broader literature (e.g. Levita et al., 2016; Stobie et al., 2007), behavioural 
Table 4. Multiple (stepped) linear regression modelling for prediction of technique use based on therapists' clinical practice characteristics and internal states

\begin{tabular}{|c|c|c|c|c|c|c|}
\hline \multicolumn{7}{|c|}{ Technique use based on therapists' clinical practice } \\
\hline \multirow[b]{2}{*}{ Dependent variable } & \multicolumn{2}{|c|}{ Overall effect } & \multirow[b]{2}{*}{ Independent variable } & \multirow[b]{2}{*}{$t$} & \multirow[b]{2}{*}{$p$} & \multirow[b]{2}{*}{ Beta } \\
\hline & $F$ & $\begin{array}{l}\text { \% variance } \\
\text { explained }\end{array}$ & & & & \\
\hline \multirow[t]{2}{*}{ All CBT techniques } & $7.98^{\star \star \star}$ & 8.8 & $\begin{array}{l}\text { Hours spent with clients per } \\
\text { week }\end{array}$ & 3.96 & $<.001$ & .333 \\
\hline & & & Hours worked per week & 2.43 & .016 & -.209 \\
\hline $\begin{array}{l}\text { Psychoeducation and general CBT } \\
\text { techniques }\end{array}$ & $5.21^{\star}$ & 2.7 & $\begin{array}{l}\text { Hours spent with clients per } \\
\text { week }\end{array}$ & 2.83 & .024 & .185 \\
\hline \multirow[t]{3}{*}{ Cognitive techniques } & $5.84^{\star \star \star}$ & 10.8 & $\begin{array}{l}\text { Hours spent with clients per } \\
\text { week }\end{array}$ & 2.91 & .004 & .249 \\
\hline & & & Hours worked per week & 2.44 & .016 & -.207 \\
\hline & & & Number of sessions & 2.44 & .016 & .193 \\
\hline Behavioural techniques & - & - & - & - & - & - \\
\hline Non-CBT techniques & $5.69^{*}$ & 3.2 & Supervision (received) & 2.39 & .018 & .196 \\
\hline \multicolumn{7}{|c|}{ Technique use based on therapists' internal state } \\
\hline & \multicolumn{2}{|c|}{ Overall effect } & & \multirow[b]{2}{*}{$t$} & \multirow[b]{2}{*}{ Beta } & \multirow[b]{2}{*}{$P$} \\
\hline Dependent variable & $F$ & $\begin{array}{l}\text { \% variance } \\
\text { explained }\end{array}$ & Independent variable & & & \\
\hline All CBT techniques & $4.30^{\star}$ & 2.2 & Prospective anxiety & 2.07 & -.168 & .040 \\
\hline \multirow[b]{2}{*}{ Dependent variable } & \multicolumn{2}{|c|}{ Overall effect } & & \multirow[b]{2}{*}{$t$} & \multirow[b]{2}{*}{ Beta } & \multirow[b]{2}{*}{$P$} \\
\hline & $F$ & $\begin{array}{l}\text { \% variance } \\
\text { explained }\end{array}$ & Independent variable & & & \\
\hline $\begin{array}{l}\text { Psychoeducation and general CBT } \\
\text { techniques }\end{array}$ & $3.95^{\star}$ & 1.9 & $\begin{array}{l}\text { Negative attitudes towards } \\
\text { CBT }\end{array}$ & 1.99 & -.160 & .049 \\
\hline Cognitive techniques & - & - & - & - & - & - \\
\hline Behavioural techniques & $8.08^{\star \star}$ & 4.5 & Inhibitory anxiety & 2.84 & -.226 & .005 \\
\hline Non-CBT techniques & $7.07^{\star \star}$ & 3.9 & Self-esteem & 2.66 & .214 & .009 \\
\hline
\end{tabular}

${ }^{*} p<.05$

${ }^{\star \star} p<.01 ;$

${ }^{\star * \star *} p<.001$

methods were used less by therapists who were more anxious. Finally, the level of experience of working with patients with anxiety disorders seems to be related to a greater use of CBT techniques overall.

These findings support previous research regarding the role of therapist characteristics. For example, the role of therapist anxiety in this study replicates the finding that therapists who are anxious are less likely to use behavioural techniques, such as exposure (Meyer et al., 2014; Levita et al., 2016; Turner et al., 2014; Waller et al., 2012). Similarly, the role of therapists' negative attitudes to CBT is compatible with prior findings that therapists who hold more negative attitudes to a therapeutic method are more likely to under-utilize or leave out key techniques (Deacon et al., 2013).

The clinical implications from these findings reveal an interesting pattern with regard to each of the technique clusters. Considering behavioural techniques, these techniques were used the least, and therapists with greater inhibitory anxiety were less likely to employ this group of techniques. The under-utilization of this technique is particularly problematic amongst therapists treating anxiety, obsessive and trauma disorders. Such techniques, particularly exposure, have been shown to be the most influential component in treating clients suffering from one of these disorders, with better outcomes and maintenance than other approaches 
that do not include exposure (Barlow et al., 1989; Clark et al., 2006; Cottraux et al., 2001; Feske and Chambless, 1995; Foa et al., 1999; Foa et al., 2005, Öst, 1989; Sánchez-Meca et al., 2010; Zlomke and Davis, 2008). The results do not indicate any other internal state or practice characteristic that is associated with an increased use of behavioural techniques.

Considering cognitive techniques, CBT therapists who held more negative views of CBT were less likely to employ these techniques. In contrast, cognitive techniques were likely to spend longer delivering a course of therapy and to work more hours in the week. It might take some therapists longer to feel comfortable enough to employ key therapeutic techniques and challenge client cognitions. Alternatively, they might be using fewer behavioural techniques, and hence being less effective.

CBT therapists who received more supervision or had greater levels of self-esteem were more likely to use these non-CBT techniques. These findings might imply that supervisory drift is occurring (Simpson-Southward et al., 2016; Simpson-Southward et al., 2017), and that therapists have greater self-belief and do not see as strong a need to focus on evidence-based approaches.

These findings require elaboration in future research. It is possible that some therapists had positive and justifiable reasons for deviating from evidence-based practice, although it is unlikely that this could have been the case for so many individuals. However, as this study did not assess why therapists under-utilized techniques, there may have been reasons that satisfactorily address why these sets of techniques were the least used. In addition, supervision might not be as effective as therapists expect in helping adherence to CBT protocols when CBT is the prescribed treatment. Other research (i.e. Simpson-Southward et al., 2017) has highlighted a number of issues regarding the adequacy of clinical supervision models. This study builds on and extends those conclusions by indicating a positive association between supervision and the use of non-CBT techniques amongst CBT therapists.

This study has a number of limitations. As this study uses self-report measures, the level of use of clinical techniques has not been ascertained concretely, and further research using observational methods is needed to confirm these findings and their implications. An alternative approach to addressing this limitation may be to use a more direct line of questioning (e.g. 'reflecting on the last 10 sessions you have had with a client with an anxiety disorder'). Another limitation might be the length of the TMQ, as many therapists stopped at or during this portion of the study. Not only is there the issue of self-selection bias, but a large proportion of the therapists were engaged in training - both factors that might have skewed the findings. In addition this postqualification training has not been assessed to determine if exposure was included, nor has prequalification been assessed similarly. Therefore, it is unclear if UK therapists are experiencing the same issues with training as therapists in the US (see Becker et al., 2004). Finally, some of the measures require refinement. For example, the TMQ would benefit from questions regarding graded exposure, interoceptive exposure, and non-exposure-based behavioural techniques. In addition to this issue, while exposure is the most supported approach to treating anxiety disorders, CBT therapists may be relaying up other forms of behavioural experiments. Therefore, future iterations of the TMQ may reflect a different practice outcome if a question on behavioural experiments in general was included. In addition, these refinements may need to include looking at the grouping of the techniques. Fortunately, those that may be considered part of CBT (or therapy overall, such as reflective listening) are not part of the elements that CBT research indicate as driving forces (e.g. exposure) in addressing anxiety disorders and, therefore, should not skew the results of this current research. In addition, the vagueness on some items could have potentially skewed the results either way, although these items (e.g. giving of homework) were relatively minor compared with the more explicitly addressed items (e.g. in vivo exposure).

Further research is needed to find ways to ensure optimal delivery of CBT. In particular, it will be important to determine the impact of factors such as clinician anxiety and clinical practice features on therapeutic outcomes, using actuarial data (e.g. outcome reports, observation of 
therapy sessions). Furthermore, it is necessary to assess CBT therapists' rationales regarding their use (or omission) of techniques when treating anxiety disorders. As therapist drift occurs without evidence supporting therapists' deviations from protocols (Waller, 2009), future studies should take into account the justifications that therapists advance for the decisions that they make. In addition and in light of these findings, the study of Becker et al. (2004) should be replicated in the UK to identify potential issues in training that lead to the under-utilization of these core techniques.

To conclude, many CBT therapists do not employ key CBT techniques (e.g. exposure). Appropriate education, training and supervision are needed to ensure competence and adherence (Waller and Turner, 2016). For example, training for therapists could be adapted to address their anxiety and negative attitudes towards CBT (Farrell et al., 2013; Meyer et al., 2014), and supervision could focus explicitly on client outcomes (Simpson-Southward et al., 2017).

Author ORCIDs. (D) Zachary Parker, 0000-0002-8349-2172; Glenn Waller, 0000-0001-7794-9546

Acknowledgements. None.

Financial support. This research received no specific grant from any funding agency, commercial or not-for-profit sectors.

Conflicts of interest. Zachary Parker and Glenn Waller have no conflicts of interest with respect to this publication.

Ethical statement. This study received ethical approval from the University of Sheffield, Department of Psychology Research Ethics Committee. It met the criteria of the Ethical Principles of Psychologists and the Code of Conduct (American Psychological Association, 2003).

Key practice points

(1) CBT clinicians appear to under-utilize behavioural techniques for anxiety disorders.

(2) That under-utilization is related to clinician anxiety and negative attitudes to CBT.

(3) Supervisors need to attend to how well clinicians are adhering to the principles and practice of CBT.

\section{Further reading}

Brosan, L, Reynolds, S, Moore, RG (2008). Self-evaluation of cognitive therapy performance: do therapists know how competent they are? Behavioural and Cognitive Psychotherapy, 36, 581-587. doi: 10.1017/S1352465808004438

Stobie, B, Taylor, T, Quigley, A, Ewing, S (2007). 'Contents may vary': a pilot study of treatment histories of OCD patients. Behavioural and Cognitive Psychotherapy, 35, 273-282. doi: 10.1017/S135246580700358X

Waller, G, Turner, H (2016). Therapist drift redux: why well-meaning clinicians fail to deliver evidence-based therapy, and how to get back on track. Behavior Therapy and Research, 77, 129-137. doi:10.1016/j.brat.2015.12.005

\section{References}

Abramowitz, JS, Taylor, S, McKay, D (2012). Exposure-based treatment for obsessive compulsive disorder. In G. Steketee (ed), The Oxford Handbook of Obsessive Compulsive and Spectrum Disorders (pp. 322-344). New York, NY, USA: Oxford University Press.

Addis, ME, Krasnow, AD (2000). A national survey of practicing psychologists' attitudes towards psychotherapy treatment manuals. Journal of Consulting and Clinical Psychology, 68, 331-339. doi: 10.1036//0022-006x.68.2

Addis, ME, Wade, WA, Hatgis, C (1999). Barriers to dissemination of evidence-based practices: addressing practitioners' concerns about manual-based psychotherapies. Clinical Psychology, 6, 430-441. doi: 10.1093/clipsy.6.4.430

American Psychological Association (2003). Ethical Principles of Psychologists and Code of Conduct. Available at: https:// www.apa.org/ethics/code/

Barlow, DH, Craske, MG, Cerny, JA, Klosko, JS (1989). Behavioral treatment for panic disorder. Behavior Therapy, 20, 261282. doi: 10.1016/S0005-7894(89)80073-5

Becker, CB, Zayfert, C, Anderson, E (2004). A survey of psychologists' attitudes towards and utilization of exposure for PTSD. Behaviour Research and Therapy, 42, 277-292. doi: 10.1016/S0005-7967(03)00138-4 
Bradley, R, Greene, J, Russ, E, Dutra, L, Westen, D (2005). A multidimensional meta-analysis of psychotherapy for PTSD. American Journal of Psychiatry, 162, 214-227.

Brosan, L, Reynolds, S, Moore, RG (2006). Factors associated with competence in cognitive therapists. Behavioural and Cognitive Psychotherapy, 35, 179-190. doi: 10.1017/S1352465806003304

Brosan, L, Reynolds, S, Moore, RG (2008). Self-evaluation of cognitive therapy performance: do therapists know how competent they are? Behavioural and Cognitive Psychotherapy, 36, 581-587. doi: 10.1017/S1352465808004438

Carleton, RN, Norton, MA, Asmundson, GJG (2007). Fearing the unknown: a short version of the Intolerance of Uncertainty Scale. Journal of Anxiety Disorders, 21, 105-117. doi: 10.1016/j.janxdis.2006.03.014

Clark, DA (2007). Cognitive-Behavioral Therapy for OCD (paperback edn). New York, NY, USA: Guilford Press.

Clark, DA, Beck, AT (2010). Cognitive Therapy of Anxiety Disorders: Science and Practice (paperback edn). New York, NY, USA: Guilford Press.

Clark, DM, Ehlers, A, Hackmann, A, McManus, F, Fennell, M, Grey, N, . . \& Wild, J. (2006). Cognitive therapy versus exposure and applied relaxation in social phobia: a randomized controlled trial. Journal of Consulting and Clinical Psychology, 74, 568-578. doi: 10.1037/0022-006X.74.3.568

Cottraux, J, Note, I, Yao, SN, Lafont, S, Note, B, Mollard, E, Sauteraud, A, Bourgeois, M, Dartigies, JF (2001). A randomized controlled trial of cognitive therapy versus intensive behavior therapy in obsessive compulsive disorder. Psychotherapy and Psychosomatics, 70, 288-297.

Craske, MG, Barlow, DH (2008). Panic disorder and agoraphobia. In DH Barlow (ed), Clinical Handbook of Psychological Disorders: A Step-by-Step Treatment Manual (4 ${ }^{\text {th }}$ edn, pp. 1-64). New York, NY, USA: Guilford Press.

Deacon, BJ, Farrell, NR, Kemp, JJ, Dixon, LJ, Sy, JT, Zhang, AR, McGrath, PB (2013). Assessing therapist reservations about exposure therapy for anxiety disorders: the Therapist Beliefs about Exposure Scale. Journal of Anxiety Disorders, 27, 772-780. doi: 10.1016/j.janxdis.2013.04.006

Dugas, MJ, Fresston, MH, Ladouceur, R (1997). Intolerance of uncertainty and problem orientation in worry. Cognitive Therapy and Worry, 21, 593-606.

Eddy, KT, Dutra, L, Bradley, R, Westen, D (2004). A multidimensional meta-analysis of psychotherapy and pharmacotherapy for obsessive-compulsive disorder. Clinical Psychology Review, 24, 1011-1030. doi: 10.1016/j.cpr.2004.08.004

Fedoroff, IC, Taylor, S (2001). Psychological and pharmacological treatments of social phobia: a meta-analysis. Journal of Clinical Psychopharmacology, 21, 311-324.

Farrell, NR, Deacon, BJ, Dixon, LJ, Lickel, JJ (2013). Theory-based training strategies for modifying practitioner concerns about exposure therapy. Journal of Anxiety Disorders, 27, 781-787. doi: 10.1016/j.janxdis.2013.09.003

Feske, U, Chambless, DL (1995). Cognitive behavioral versus exposure only treatment for social phobia: a meta-analysis. Behavior Therapy, 26, 695-720.

Foa, EB, Dancu, VC, Hembree, EA, Jaycox, LH, Meadows, EA, Street, GP (1999). A comparison of exposure therapy, stress inoculation training and their combination for reducing posttraumatic stress disorder in female assault victims. Journal of Clinical and Consulting Psychology, 67, 194-200.

Foa, EB, Hembree, EA, Cahill, SP, Rauch, SAM, Riggs, DS, Feeny, NC, Yadin, E (2005). Randomized trial of prolonged exposure for posttraumatic stress disorder with and without cognitive restructuring: outcome at academic and community clinics. Journal of Consulting and Clinical Psychology, 73, 953-964. doi: 10.1037/0022-006X.73.5.953

Franklin, ME, Foa, EB (2008). Obsessive-compulsive disorder. In DH Barlow (ed), Clinical Handbook of Psychological Disorders: A Step-by-Step Treatment Manual (4 ${ }^{\text {th }}$ edn, pp. 164-215). New York, NY, USA: Guildford Press.

Hansen, NB, Lambert, MJ, Forman, EM (2002). The psychology dose-response effect and its implications for treatment delivery services. Clinical Psychology: Science and Practice, 9, 308-327.

Hawkes, LD, Provencher, MD (2011). Schema theory and schema therapy in mood and anxiety disorders: a review. Journal of Cognitive Psychotherapy: An International Quarterly, 25, 257-276.

Hofmann, SG, Smits, JAJ (2008). Cognitive-behavioral therapy for adult anxiety disorders: a meta-analysis of randomized placebo-controlled trials. Journal of Clinical Psychiatry, 69, 521-632.

Kearney, CA (2005). Social Anxiety and Social Phobia in Youth: Characteristics, Assessment, and Psychological Treatment. Available at: https://www.springer.com/us/book/9780387225913

Khawaja, NG, Lai, NH (2010). A comparison of the 27-item and 12-item intolerance of uncertainty scales. Clinical Psychologist, 14, 97-106. doi: 10.1080/13284207.2010.502542

Koch, EI, Gloster, AT, Waller, SA (2007). Exposure treatments for panic disorder with and without agoraphobia. In DS Richard, and D Lauterbach (eds), Comprehensive Handbook of Exposure Therapies. New York,NY, USA: Academic Press.

Ladouceur, R, Gosselin, P, Dugas, MJ (2000). Experimental manipulation of intolerance of uncertainty: a study of a theoretical model of worry. Behaviour Research and Theory, 38, 933-941.

Levita, L, Salas Duhne, PG, Girling, C, Waller, G (2016). Facets of clinicians' anxiety and the delivery of cognitive behavioral therapy. Behaviour Research and Therapy, 77, 157-161. doi: 10.1016/j.brat.2015.12.015

Martin, B (2013). Treatment of anxiety. In Low intensity cognitive behaviour therapy: A practitioner's guide (pp. 218-252). Los Angeles, USA: Sage. 
Meehl, PE (1986). Causes and effects of my disturbing little book. Journal of Personality Assessment, 50, 370-375.

Metalsky, GI, Joiner, TE, Hardin, TS, Abramson, LY (1993). Depressive reactions to failure in a naturalistic setting: a test of the hopelessness and self-esteem theories of depression. Journal of Abnormal Psychology, 102, 101-109.

Meyer, JM, Farrell, NR, Kemp, JJ, Blakey, SM, Deacon, BJ (2014). Why do clinicians exclude anxious clients from exposure therapy? Behaviour Research and Therapy, 54, 49-53. doi: 10.1016/j.brat.2014.01.004

Norton, PJ, Price, EC (2007). A meta-analytic review of adult cognitive-behavioral treatment outcome across the anxiety disorders. Journal of Nervous and Mental Disease, 195, 521-531.

Olantunji, BO, Deacon, BJ.,Abramowitz, JS (2009). The cruelest cure? Ethical issues in the implementation of exposurebased treatments. Cognitive and Behavioural Practice, 16, 172-180. doi: 10.1016/j.cbpra.2008.07.003

Öst, LG (1989). One-session treatment for specific phobias. Behaviour Research and Therapy, 27, 1-7.

Otto, MW, Pollack, MH, Maki, KM (2000). Empirically supported treatments for panic disorder: costs, benefits, and stepped care. Journal of Consulting and Clinical Psychology, 68, 556-563. doi: 10.1037/0022-006X.68.4.556

Parker, ZJ, Waller, G (2015). Factors related to psychotherapists' self-assessment when treating anxiety and other disorders. Behaviour Research and Therapy, 66, 1-7. doi: 10.1016/j.brat.2014.12.010

Parker, ZJ, Waller, G (2017). Development and validation of the Negative Attitudes towards CBT Scale. Behavioural and Cognitive Psychotherapy, 45, 629-646. doi: 10.1017/S1352465817000170

Resick, PA, Monson, CM, Rizvi, SL (2008). Posttraumatic stress disorder. In DH Barlow (ed), Clinical Handbook of Psychological Disorders: A Step-By-Step Treatment Manual (4 $4^{\text {th }}$ edn, pp. 65-122). New York, NY, USA: Guilford Press.

Rosenberg, M (1965). Society and the Adolescent Self-Image. Princeton, NJ, USA: Princeton University Press.

Sánchez-Meca, J, Rosa-Alcázar, AI, Marín-Martínez, F, Gómez-Conesa, A (2010). Psychological treatment of panic disorder with or without agoraphobia: A meta-analysis. Clinical Psychology Review, 30, 37-50. doi: 10.1016/j.cpr.2009.08.011

Schmitt, DP, Allik, J (2005). Simultaneous administration of the Rosenberg Self-Esteem Scale in 53 nations: exploring the universal and culture-specific features of global self-esteem. Journal of Personality and Social Psychology, 89, 623-642. doi: 10.1037/0022-3514.89.4.623

Simpson-Southward, C, Waller, G, Hardy, GE (2016). Supervision in the treatment of depression: an experimental study of the role of therapist gender and anxiety. Behaviour Research and Therapy, 77, 17-22. doi: 10.1016/j.brat.2015.11.013

Simpson-Southward, C, Waller, G, Hardy, GE (2017). How do we know what makes for 'best practice' in clinical supervision for psychological therapists? A content analysis of supervisory models and approaches. Clinical Psychology \& Psychotherapy, 24, 1228-1245. doi: 10.1002/cpp.2084.

Sinclair, SJ, Blais, MA, Gansler, DA, Sandberg, E, Bistis, K, LoCicero, A (2010). Psychometric properties of the Rosenberg Self-Esteem Scale: overall and across demographic groups living within the United States. Evaluation and the Health Professions, 33, 56-80. doi: 10.1177/0163278709356187

Stobie, B, Taylor, T, Quigley, A, Ewing, S (2007). 'Contents may vary': a pilot study of treatment histories of OCD patients. Behavioural and Cognitive Psychotherapy, 35, 273-282. doi: 10.1017/S135246580700358X

Turk, CL, Heimberg, RG, Magee, L (2008). Social anxiety disorder. In DH Barlow (ed), Clinical Handbook of Psychological Disorders: A Step-by-Step Treatment Manual (4 ${ }^{\text {th }}$ edn, pp. 123-163). New York, NY, USA: Guilford Press.

Turner, H, Tatham, M, Lant, M, Mountford, VA, Waller, G (2014). Clinicians' concerns about delivering cognitivebehavioural therapy for eating disorders. Behaviour Research and Therapy, 57, 38-42. doi: 10.1016/j.brat.2014.04.003

Waller, G (2009). Evidence-based treatment and therapist drift. Behaviour Research and Theory, 47, 119-127. doi: 10.1016/j. brat.2008.10.018

Waller, G, Stringer, H, Meyer, C (2012). What cognitive behavioral techniques do therapist report using when delivering cognitive behavioral therapy for eating disorders? Journal of Consulting and Clinical Psychology, 80, 171-175. doi: 10.1037/ a0026559

Waller, G, Turner, H (2016). Therapist drift redux: why well-meaning clinicians fail to deliver evidence-based therapy, and how to get back on track. Behavior Therapy and Research, 77, 129-137. doi: 10.1016/j.brat.2015.12.005

Westen, D, Morrison, K (2001). A multidimensional meta-analysis of treatments for depression, panic, and generalized anxiety disorder: an empirical examination of the status of empirically supported therapies. Journal of Consulting and Clinical Psychology, 69, 875-899.

Whittal, ML, Robichaud, M (2012) Cognitive treatment for OCD. In G Steketee (ed), The Oxford Handbook of Obsessive Compulsive and Spectrum Disorders (pp. 345-364). New York, NY, USA: Oxford University Press.

Zlomke, K, Davis, TE (2008). One-session treatment of specific phobias: a detailed description and review of treatment efficacy. Behavior Therapy, 39, 207-223. doi: 10.1016/j.beth.2007.07.003

Cite this article: Parker ZJ and Waller G. Psychotherapists' reports of technique use when treating anxiety disorders: factors associated with specific technique use. The Cognitive Behaviour Therapist. https://doi.org/10.1017/S1754470X19000205 